\title{
UNIVERSIDAD Y ÉTICA PROFESIONAL
}

\section{Professional ethics as a University subject}

\section{Université et étbique professionnelle}

\author{
Juan Manuel COBO SUERO \\ Universidad Pontificia Comillas de Madrid. Facultad de Ciencias Humanas y \\ Sociales. Departamento de Educación. Universidad Comillas, 7. 28049 Madrid. \\ Correo-e: cobo@cbs.upco.es
}

Fecha de recepción: diciembre de 2003

Fecha de aceptación definitiva: marzo de 2004

BIBLID [(1130-3743) 15, 2003, 259-276]

RESUMEN

En el marco del derecho a la formación permanente, la formación en ética profesional representa un paso en la educación moral de las personas, cuyo espacio más lógico de aprendizaje coincide con la formación profesional inicial (en la universidad, diremos en adelante tomando la parte por el todo). En lo que respecta a la relevancia de estc aprendizaje, a la importancia social de la ética profesional hay que añadir su importancia para la realización y el vivir con sentido del profesional. Para la elucidación de los principios/valores de esta ética profesional hay que acudir a dos fuentes: la tradicional de los filósofos éticos y pensadores afines y la de los colectivos de profesionales que elaboran los códigos éticos o deontológicos. De la conjunción de ambas resultan cinco principios/valores principales: 1) dignidad, libertad, igualdad y derechos humanos, 2) justicia conmutativa y social, 3) autonomía profesional y deontológica, 4) beneficencia y 5) responsabilidad profesional. La enseñanza-aprendizaje de la ética profesional interpela al conjunto del profesorado, lo que no excusa de su inclusión como asignatura en los planes de estudio. Para esta asignatura se proponen cuatro bloques de contenidos y algunas sugerencias metodológicas. El artículo termina con algunas informaciones sobre la enseñanza de la ética profesional en la universidad española.

Palabras clave: profesión, formación profesional, ética de las profesiones, principios-valores, ética profesional, enseñanza-aprendizaje, realización profesional. 


\section{SUMMARY}

Within the framework of Continuing Education, the study of professional Ethics appears as a natural step towards the moral development of every person. This should logically happen at the start of professional formation (within the University, as will be explained later in more detail). The importance of this type of learning bears upon the social aspects of professional Ethics and also upon the personal meaning of professional activity. To clarify the principles and values of professional Ethics we must study two sources: the traditional work of philosophers of Ethics and related thinkers, and the contributions of people involved in the professions, who develop ethical norms and codes of conduct. The interaction of both sources brings up five main principles or values: 1) Personal dignity, freedom, equality and human rights, 2) Social and commutative justice, 3) Professional autonomy and codes of behavior, 4) Beneficence, 5) Professional responsibility. Teaching and learning professional Ethics involves the entire Faculty, but this fact does not imply its absence as a subject in the academic curriculum. To include it as a specific topic, four main areas to be developed are proposed, as well as some methodological guideliness. This paper finally gives some actual information about the teaching of professional Ethics in Spanish Universities.

Key words: profession, professional formation, ethics of the professions, principlesvalues, professional ethics, teaching-learning, professional achievement.

\section{SOMMAIRE}

Dans le cadre du droit à la formation tout au long de la vie, la formation en éthique professionnelle represente un pas important vers l'éducation morale des personnes, dont l'espace le plus logique pour l'apprentissage coincide avec la formation professionnelle initiale (dorénavant l'université, tout en appliquant le principe de la partie pour l'ensemble). En ce qui concerne á la valeur de cet apprentissage, á l'importance sociale de l'éthique professionnelle faut-il ajouter son importance pour l'épanouissement personnel et le fait de vivre avec le sens du professionnel. Si l'on veut éclaircir les principes/valeurs de cette éthique professionnelle il faut consulter deux sources: la source traditionnelle des philosophes éthiques et penseurs analogues ainsi que celle des collectifs de profesionnels élaborant les codes éthiques ou déontologiques, dont cinq principes/valeurs principales se sont conjugués: 1) dignité, liberté, égalité et droits de l'homme, 2) justice commutative et sociale, 3) autonomie professionnelle et déontologique, 4) bienfaisance 5) responsabilité professionnelle. L'enseignement-apprentissage de l'éthique professionnelle interpelle l'ensemble des enseignants, étant inéludable son inclusion en tant que matière aux plans d'études. Pour cette matière on propose quatre groupes de contenus et quelques propositions méthodologiques. Finalement, le travail presente des informations sur l'enseignement de l'éthique professionnelle dans l'Université espagnole.

Mots clef: profession, formation profesionnelle, éthique des professions, principesvaleurs, éthique profesionnelle, enseignement-apprentissage, épanouissemen profesionnelle. 


\section{INTRODUCCIÓN}

Es significativo que un número monográfico de esta prestigiosa revista dedicado a la educación moral publique un artículo sobre el aprendizaje de la ética profesional en la Universidad.

Es significativo porque quiere decir que en nuestro tiempo no se contempla ya a la educación moral como un aprendizaje propio de niños y de estudiantes de secundaria - como sucedía hasta tiempos no muy lejanos-, sino como algo que ha de procurarse también en otras etapas de la vida. Y es coherente, por otra parte, con el deber y el derecho de todas las personas a la formación permanente ${ }^{1}$, una formación diversa obviamente según las circunstancias y necesidades de cada persona pero que, por supuesto, puede comprender aspectos éticos.

Pues bien, con este transfondo y marco de la necesidad, deber y derecho de formación moral a lo largo de la vida parece lógico situar el aprendizaje de la ética profesional en el momento y en las instituciones correspondientes a la formación profesional inicial de las personas. En la universidad diremos aquí para agilizar el texto tomando la parte por el todo, ya que también las instituciones de formación profesional no universitarias deben procurar a sus estudiantes esta formación.

La razón es que la relación entre universidad y aprendizaje de la ética profesional es algo evidente, si se considera que del profesional se espera no sólo competencia, sino también que use su competencia y desempeñe su servicio con ética. Por consiguiente, si la universidad es la encargada de facilitar el aprendizaje de esa competencia, lógico será que junto a ella procure también a los estudiantes el aprendizaje de la ética profesional que ha de acompañar el ejercicio de aquélla.

\section{IMPORTANCIA SOCIAL DE LA ÉTICA PROFESIONAL}

La comprensión de la necesidad de proceder con ética profesional ha acompañado desde siempre a la práctica de la medicina y de otras profesiones con fuerte raigambre histórica y social (judicatura, comercio...). Ahora bien, en la actualidad, la necesidad de un proceder profesional ético se ha hecho especialmente visible en los medios económicos y políticos (no sólo de países tradicionalmente corruptos, sino también de los países más desarrollados) y se ha generalizado a todas las profesiones.

En realidad, en estos últimos países hay hoy una especial sensibilidad social ante la ética de los profesionales: se airean los fallos, la opinión pública reclama medidas legales y judiciales para regular su cumplimiento y se apela a ella en la propaganda porque "vende".

1. “Toda persona tiene derecho a la educación y al acceso a la formación profesional y permanente: Carta de los derechos Fundamentales de la Unión Europea, art. 14, 1. 
Por todo ello, se comprende la responsabilidad sobre la ética de los profesionales que han de asumir los Colegios Profesionales, a los que la legislación española encomienda "ordenar en el ámbito de su competencia la actividad profesional de los colegiados, velando por la ética y dignidad profesional y por el respeto debido a los derechos de los particulares, y ejercer la facultad disciplinaria en el orden profesional y colegial" (Ley de Colegios Profesionales, art. 5 i).

$\mathrm{Y}$, en coherencia con lo anterior, se comprende también el interés de los Colegios y Asociaciones Profesionales por disponer de un código de conducta profesional propio (el código ético o deontológico de la profesión) y por darlo a conocer ${ }^{2}$.

\section{3. ÉTICA Y REALIZACIÓN PROFESIONAL}

Junto a esta importancia social de la ética profesional es conveniente considerar también la importancia del proceder ético para la realización bumana del profesional. Esta relación, ética-realización humana, está llena de sentido antropológico y filosófico, como veremos, y por lo mismo debe constituir el principio $y$ fundamento de la formación en ética profesional en la universidad.

Para introducir al sentido antropológico y filosófico de la ética profesional, comenzaremos tomando conciencia del carácter teleológico de la ética, ya que la ética relaciona la conducta bumana con la búsqueda del bien (fin inmediato) y con la búsqueda de la felicidad (fin último), la cual —si no hay otros factores vitales que interfieran interrumpiendo el proceso- subsigue a esa actitud y proceder de búsqueda del bien.

Pues bien, este proceso se cumple exactamente en la praxis de la ética profesional, ya que las profesiones tienen su razón de ser en la búsqueda de algún bien de tal forma que, prosiguiendo la consecución de ese bien, el profesional alcanza su realización y la correspondiente felicidad en ese orden de su existencia, en su vida profesional. Veámoslo más en detalle.

Decimos que las profesiones tienen su razón de ser en la búsqueda de algún bien, ¿por qué? Porque las profesiones no son producto del azar o del capricho humano: nacen y en las sociedades actuales son reconocidas social y legalmente como tales porque responden a alguna necesidad de las personas que constituyen una sociedad o de la sociedad en su conjunto. Es decir, las profesiones nacen para proporcionar algún bien (productos o servicios) a las personas y a la sociedad. Por eso, se comprende la afirmación de Hortal de que "lo primero y más fundamental sobre lo que se tiene que reflexionar en un curso de ética profesional es sobre los

2. Unas profesiones llaman a su código de conducta código ético, poniendo el acento en su fundamentación filosófica y científica, otras código deontológico, subrayando que es algo con lo que el profesional se compromete libremente y que debe cumplir, y otras código ético y deontológico. Sobre el tema y la historia del término deontología en este contexto puede verse CoBo (2001, 31 y ss.). 
fines o bienes intrínsecos a los que tiende el ejercicio de cada profesión" (Hortal, 1994, 15).

Según esto, una profesión es una actividad que ocupa de forma estable a un grupo de personas en la producción de unos determinados bienes o servicios necesarios o convenientes para las sociedades. Y se comprende también que las sociedades establezcan los requisitos necesarios para ejercer las diferentes profesiones (los conocimientos teóricos y prácticos, competencias y destrezas propios y necesarios para ejercerlas) y que regulen su práctica ${ }^{3}$.

$\mathrm{Y}$ un profesional es una persona que ha adquirido unas determinadas competencias o capacidades para aportar algo, un bien (producto o servicios) en algún orden a los demás y a la sociedad: ayudar a conservar o a recuperar la salud, atender en una oficina, asesorar legalmente, producir o contribuir a la fabricación de un producto necesario o conveniente para otros, ayudar educativamente, procurar algún servicio de ocio, arreglar un aparato estropeado, conducir un servicio público...

Por consiguiente, el profesional que ejerce su profesión correctamente es una persona:

- Que con el ejercicio de su profesión está haciendo o procurando a otros el bien propio de su actividad profesional y que, por lo mismo, puede experimentar la satisfacción que acompaña a la experiencia de bacer el bien a los demás.

- Que puede experimentar, asimismo, la satisfacción del deber cumplido. Una experiencia que puede compensar en casos algunas experiencias de fracaso en la aportación del bien o en la prestación del serviciót.

- Que puede experimentar también otros sentimientos positivos, como son los de sentirse socialmente útil, o de alegría por haber encontrado un trabajo que gusta o sencillamente por tener trabajo.

- Que puede pasar por la experiencia profesional básica de sentirse realizado ejerciendo su profesión, sobre todo cuando la profesión es vocacional. Porque ¿qué sucede cuando usamos una capacidad para aquello para lo que la tenemos o adquirimos, por ejemplo la capacidad de ver, de oír, de amar, de comunicar, de aprender, de trabajar...? Que viendo, oyendo, amando, comunicando, etc., nos sentimos realizados en ese orden de actividad humana. Pues bien, esto es lo que siente el profesional que utiliza como debe sus capacidades y competencias profesionales, que ejerce

3. Una presentación más detallada y completa del concepto de profesión, su problematicidad en las cambiantes sociedades actuales y sus contextos legales en España puede verse en CoBO, J. M. (2003) Formación universitaria y educación para la ciudadanía, Revista de Educación, número extraordinario 2003 Ciudadanía y Educación, 359-375 (en concreto, en las 362-364).

4. Por ejemplo, un profesor que, habiendo puesto el máximo interés en la preparación de un curso tiene una mala evaluación por sus alumnos, puede ver atenuado su disgusto con la idea de que hizo cuanto estaba de su parte por hacerlo bien, es decir, con la idea del deber cumplido. 
correctamente su profesión: la experiencia de sentirse realizado profesionalmente.

- Que, como poso de todo o de parte de lo anterior, puede pasar también por una experiencia de sentido, por la experiencia del sentido de lo que hace. Un tipo de experiencia humana muy importante y necesario para contrarrestar y mantener el equilibrio psicológico y las ganas de vivir, dado que a lo largo de la vida todas las personas pasan también por experiencias de absurdo (la más importante la experiencia de la muerte de seres (ercanos) $)^{5}$.

- Y que con todo ello puede vivir en plenitud su ciudadania, ya que el ejercicio profesional correctamente ejercido representa la principal aportación y participación ciudadana del profesional, además de aportarle la capacitación básica (económica, social, cultural) para el ejercicio de sus demás derechos y deberes ciudadanos.

Pues bien, parece obvio concluir que una persona que pasa en todo o en parte por este conjunto de experiencias positivas es una persona feliz con su profesión, feliz en ese orden de su existencia que es su vida profesional. Y que con ello alcanza su objetivo final, el proceso ético, ya que, como veíamos más arriba, la ética relaciona la conducta bumana con la búsqueda del bien y con la felicidad que subsigue a esa actitud y proceder.

Una felicidad que, por otra parte, va acompañada y se reviste socialmente de los contextos y rasgos propios de la profesión: del éthos profesional (carácter, manera de ser) propio de la profesión, de un estatus social determinado, de sentimientos de pertenencia e identidad sociales, de corporativismo...

Con todo, no se puede ni debe obviar evidentemente en este reconocimiento de los valores antropológicos y filosóficos de la ética profesional el hecho de que no todas las personas están contentas en y con su profesión o en y con su trabajo concreto, por lo que no puede decirse en su caso que se cierra el ciclo ético, ya que no son "felices".

Así, además de las personas en las que no cabe plantear la cuestión porque carecen de trabajo y de aquellas otras que son objeto de explotación laboral, hay otras muchas personas que pueden no ser felices en su trabajo por diversos motivos: por desajuste ocupacional (haberse preparado para un tipo de trabajo y tener que trabajar en otra cosas), por el tipo de trabajo o por otras circunstancias de tipo laboral, social o económico.

Pero este hecho no anula las tesis expuestas, como el hecho de los fracasos sentimentales no anula la verdad de la felicidad que proporciona el amor. Simplemente constata una vez más que la realidad de la condición humana individual y colectiva está hecha de luces y de sombras.

5. Es lo que subyace, por ejemplo, a las actitudes de algunos profesionales que ante desgracias o problemas familiares se refugian en el trabajo. 


\section{FUENTES Y PRINCIPIOS DE LA ÉTICA DE LAS PROFESIONES}

\subsection{Fuentes de la ética de las profesiones}

Así, pues, la ética profesional que debe transmitir la universidad tiene su principio y fundamento, según lo expuesto en la toma de conciencia del bien social que corresponde procurar a la profesión de que se trata y en la comprensión del sentido antropológico y filosófico de la ética profesional: proceder éticamente conduce a una experiencia del sentido de lo que se hace, al sentimiento de realización humana y a la felicidad en la vida profesional.

Esto supuesto, nos ocupamos ahora de la ética de las profesiones, es decir, de la ética común a todas las profesiones, que cada ética profesional ha de aplicar en el ejercicio de la profesión correspondiente.

Una ética que, además de ser teleológica en el sentido explicado en el parágrafo anterior, es deontológica, porque su propuesta del buen comportamiento moral lo hace en el contexto del deber, es decir, es una iluminación sobre cómo se debe actuar en la actividad profesional (Etxeberria, 2002, 192). Y una ética que desde el primer momento ha de ser propuesta no como normativas que le vienen de fuera al profesional, sino como algo que éste adopta, como una autorregulación, ya que "lo que les da sentido en la vida moral de cada uno (a las normativas) es el haber sido asumidas por convicción, no por imposición" (Camacho, Fernández y Miralles, 2002, 21).

Pues bien, para la construcción de esta ética de las profesiones se debe atender a dos fuentes: la conformada por filósofos éticos y pensadores afines (profesores, estudiosos de la ética médica y más recientemente de la bioética), que representan la fuente tradicional en el tratamiento de estos temas, y la constituida más recientemente por los colectivos de profesionales que elaboran y promulgan códigos éticos/deontológicos, en los que proponen un modelo del "buen profesional".

Dos fuentes a las que es necesario atender porque se complementan, aunque no siempre colaboran entre sí como fuera de desear, ya que no es infrecuente que representantes del primer grupo consideren poco fundamentadas o excesivamente casuísticos los códigos de los colectivos de profesionales, y que éstos consideren demasiado abstrusos e inconcretos los planteamientos de los primeros.

Así, los filósofos y pensadores afines aportan el sentido ético y deontológico que hemos comentado y la conexión con los grandes principios de la ética general que la ética de las profesiones debe aplicar. Ahora bien, son muy dependientes de la ética médica y bioética y de la tradición kantiana, lo que hace que valoren en exceso algunos aspectos (incluyen, por ejemplo, la "no maleficencia" entre los grandes principios deontológicos) y que descuiden otros (no incluyen, en cambio, entre ellos el principio del respeto a la dignidad humana y a los derechos humanos), además de producir con frecuencia una impresión demasiado abstracta. Así, Etxeberria dirá que entre los sistemas de principios 
el más trabajado es el que proviene de la ética biomédica, pero que puede aplicarse a múltiples profesiones, y que distingue cuatro principios en una compleja interrelación: no maleficencia, beneficencia, autonomía y justicia (Etxeberría, 2002, 192, nota 5).

Y los colectivos de profesionales aportan un fuerte sentido deontológico de la profesión desde el conocimiento concreto del servicio y función sociales de la misma, de las responsabilidades profesionales, del ejercicio de la profesión científicamente planteado, de la experiencia contrastada de buenas maneras en la forma de actuar y del afrontamiento responsable de problemas. Al tiempo que sus códigos éticos o deontológicos adolecen, en cambio, por lo general de una insuficiente explicitación de los principios fundamentales de la ética de las profesiones, lo que hace que se echen de menos unas claves sintetizadoras y que los códigos éticos o deontológicos parezcan a veces una "casuística de principios": un "principio" para cada caso o situación (Cobo, 2001, 146-149).

Esto supuesto, ¿qué sistema de principios/valores para la ética de las profesiones puede proponerse a partir de estas dos fuentes? En mi opinión, el sistema de cinco principios/valores que paso a presentar. Los titulo principios/valores para subrayar que, además de criterios fundamentales del conocimiento moral sobre cómo proceder, deben constituir algo importante para el profesional, algo que valora, que forma parte de su modelo de identificación como profesional ${ }^{6}$.

\subsection{Sistema de principios/valores de la ética de las profesiones}

A. Principios de la ética general aplicados a la ética de las profesiones

1. Respetar la dignidad, la libertad, la igualdad y los derechos bumanos de los clientes o usuarios del servicio, asi como también de los compañeros y colegas $y$ de todos los ciudadanos

Como en cualquier ética aplicada, la ética de las profesiones asume y aplica al ejercicio y a la vida profesional algunos principios básicos de la ética general y el primero y al que más referencias hacen los códigos éticos/deontológicos profesionales en todas y cada una de sus partes es a este principio, el más básico y universal?

6. Publiqué este sistema por primera vez ( $\sin$ el principio de "autonomían) en el libro Ética Profesional en Ciencias Humanas y Sociales, pp. 73-126, comentando su sentido y la aplicación de los mismos en los códigos de cinco profesiones, y, en forma de cuadro, en el artículo también citado "Formación universitaria y educación para la ciudadanía". Aquí presento este cuadro algo más completo, explicado y con más matices.

7. «El reconocimiento de la dignidad única del ser bumano (sus capacidades y cualidades no tienen parangón en los demás seres que conocemos), la aceptación de la igualdad específica de todos los bombres (mujeres y varones), y el consiguiente respeto a los derechos bumanos de todos los bombres, 
En lo que se refiere en concreto a las relaciones del profesional con los clientes o usuarios de su servicio constituyen aplicaciones habituales de este principio (sin ser exhaustivos en la relación que presentamos) el respeto a su autonomía (por ejemplo, respetando su toma de decisiones en la orientación personal y profesional); el respeto a su intimidad física y psiquica (por ejemplo, en el trato al enfermo por el/la enfermero/a o en no querer saber más de lo necesario para la solución del caso por el psicólogo); el secreto profesional (no descubrir a otros lo sabido sobre alguien en el ejercicio profesional, necesario en todas las profesiones); y el trato igual a todos con independencia de diferencias individuales o grupales (algo que hay ocasión de practicar también en la mayor parte de las profesiones).

\section{Proceder siempre conforme a la justicia conmutativa $y$, en su caso, conforme a la justicia social}

Obrar conforme a la justicia es actuar reconociendo, dando o exigiendo a cada uno lo que le corresponde. Cuando en la actuación entra en juego alguna forma de intercambio, trueque o permuta, debe regir la justicia conmutativa, cuya esencia es la equidad (igualdad o equivalencia) entre lo que cada parte da y recibe. Pues bien, esta relación se da entre el profesional y el cliente o usuario del servicio, el cual debe retribuir en justicia al profesional por el servicio recabado (puede hacerlo directa o mediatamente, por ejemplo, por la seguridad social u otro seguro), así como el profesional debe aportarle en justicia el trabajo, producto o servicio correspondiente.

Pero además de esta presencia esencial de la justicia en la relación profesional, puede darse una exigencia de participación del profesional en la justicia social.

Por justicia social entendemos aquí dos $\operatorname{cosas}^{8}$. Por una parte, la justicia social es una modalidad de la justicia distributiva ${ }^{9}$, que aplica ésta en la distribución de la atención social a los derechos sociales de todos los ciudadanos. $\mathrm{O}$, dicho de otra forma, a la distribución de la atención social a las necesidades de trabajo o rentas, sanitarias, de educación, de vivienda, de participación en la sociedad del conocimiento y de acceso a las prestaciones y servicios sociales de todos los ciudadanos, para que todos las vean satisfechas al menos en unos niveles humanamente dignos.

que tienen en esa dignidad su origen y fundamento y en esa igualdad su validación universal, conforman el principio más importante de la ética.

El principio más básico y universal, porque sirve de fundamento a los demás principios (la justicia, por ejemplo, tiene en él su norte) y porque debe regir en todas las actividades de los seres humanos cuando se relacionan entre sí. (COBO, 2001, 74).

8. Con algunas actualizaciones, sigo básicamente mi estudio (1994) Contribución a la crítica de la politica social, 118-124.

9. La que tiene como campo de aplicación la distribución de bienes o cargas entre personas cuyos derecho o deber a participar en ella está acreditado. 
Y entendemos por justicia social, por otra parte, aquella justicia en la distribución de la atención a los derechos sociales de todos los seres humanos que no fundamenta únicamente el derecho a la participación en argumentos establecidos convencionalmente (los más comunes son haber pagado impuestos o tener la nacionalidad); sino que tiene en cuenta además que toda persona tiene derecho a ver atendidas sus necesidades más fundamentales por el solo hecho de ser eso, de ser persona, de ser un ser humano. Y que, por consiguiente, si vive en una sociedad capacitada para distribuir esa atención a los derechos sociales de todos, tiene derecho a participar de esa distribución aunque no haya podido cotizar o alcanzar la nacionalidad.

Pues bien, en unas sociedades con problemas de exclusión social y en un mundo con en el que cuatro quintas partes de la humanidad padecen pobreza y lacerantes carencias, la justicia social interpela a cada profesión y a los profesionales para que no queden ciudadanos sin atender en sus derechos y necesidades básicos en el sector de su incumbencia y responsabilidad ${ }^{10}$.

\section{Proceder con autonomía tanto en el ejercicio profesional como en la ética con que se debe proceder en ese ejercicio}

Es decir, proceder con autonomía tanto en el ejercicio profesional, tomando las decisiones y asumiendo las responsabilidades a que diere lugar la actuación profesional, como en la ética profesional, es decir, en las actitudes y soluciones que deban darse las situaciones profesionales éticamente dilemáticas.

En este segundo sentido no hay que olvidar que "la ética es esencialmente autónoma, ya que radica últimamente en las convicciones personales, que son las que dan sentido a las normas" (Camacho, Fernández y Miralles, 2002, 21). Y es importante observar también que no va contra esta autonomía adoptar libremente una autorregulación corporativa (el código ético o deontológico), ya que es obvio que en ética - como en cualquier otro campo- una persona no lo sabe todo, por lo que es lógico que recurra en éste al saber científico y a la experiencia de su colectivo.

10. La única profesión que conozco que se comprometa explícitamente en su código de conducta con la justicia social es la de los Diplomados en Trabajo Social, cuyo Código Deontológico dice en el Artículo 7: "Los trabajadores sociales tienen un compromiso con la justicia social".

Aunque cada vez son más frecuentes planteamientos en línea con la justicia social en ámbitos de la ética empresarial (animando a crear empresas y trabajo), de la ingeniería (motivando a trabajar por el desarrollo), de la medicina (impulsando un medicina de calidad para todos)... Así como, también, cada vez son más los colectivos profesionales que responden a imperativos mundiales de esta justicia social con la promoción de voluntariados sin fronteras en su campo profesional. 
B. Principios propios de la ética de las profesiones

4. Poner los conocimientos y destrezas profesionales al servicio del bien que debe proporcionar la profesión a los clientes o usuarios del servicio profesional

Este principio, conocido como "principio de beneficencia" [etimológicamente, principio de bene efficere (latín): de obrar, hacer, proceder bien], es un principio específico de la ética de las profesiones, que enraíza con la razón de ser de las mismas, proporcionar algún bien (producto o servicio) a otras personas y a la sociedad, como hemos visto. Es, por lo mismo, un principio cuya puesta en práctica debe acompañar habitualmente la vida del profesional, transcendiéndola de sentido y haciendo del profesional una persona realizada.

Por ello, no es de extrañar que en las preguntas "¿cuál es el bien que yo puedo y debo realizar?" o “ccómo aporto yo aquí más bien o hago mejor el bien?» radique normalmente la clave para resolver situaciones dilemáticas. Y que quebrantarle contradictoriamente, es decir, emplear los conocimientos y destrezas profesionales para hacer el mal, constituya la más grave de las infracciones de la ética profesional. Es, por ejemplo, el caso del juez que prevarica emitiendo una sentencia injusta a sabiendas de que lo es; del policía o el psicólogo que colabora con la tortura; del médico que termina sin justificación con alguna vida humana; del profesor que suspende a alguien para perjudicarle, etc. ${ }^{11}$.

Aunque emplear para hacer el mal los conocimientos y destrezas profesionales o el poder que otorga la profesión no son las únicas infracciones contra el principio de beneficencia. Está además su utilización para fines espúreos; por ejemplo, para obtener beneficios ajenos a los normales, propios y coherentes con el ejercicio profesional, como pueden ser un enriquecimiento injustificado o la obtención de prebendas laborales o sociales para familiares o amigos.

Es lo que se conoce como "tráfico de influencias" (traficar con la capacidad de influir), del que la utilización de "información privilegiada" (información obtenida en el ejercicio profesional) para obtener ese tipo de beneficios espurios constituye un caso particular. Todo un mundo de posibles infracciones de la ética profesional, que han contribuido de forma muy importante a la toma de conciencia social de la importancia y necesidad de ética profesional en las sociedades actuales.

11. La importancia de las infracciones que contradicen el principio de beneficencia ha conducido a reconocer en la tradición de la ética profesional médica y filosófica también como principio de esta ética la no maleficencia (no hacer mal), como hemos visto. Puede verse la explicación que ofrece del mismo HORTAL (2002, 163-172.)

Personalmente creo que no hace falta proponer como principio no hacer el mal con los conocimientos y destrezas profesionales, una vez establecido el principio de beneficencia (hacer el bien) como central en el ejercicio de la profesión. 


\section{Proceder siempre con responsabilidad profesional}

Este principio atraviesa de parte a parte a muchos códigos ético/deontológicos, porque para los colectivos que los han elaborado la responsabilidad profesional es una realidad muy valorada.

No es que los otros principios no estén presentes en estos códigos; precisamente recorrer su articulado cayendo en la cuenta del principio ético que se pone en juego en cada artículo es uno de los caminos más enriquecedores en la pedagogía de la ética profesional, ya que conduce a entender tanto la presencia de la ética en la vida profesional, como el valor ético del proceder profesional científico y de determinadas aportaciones de la experiencia profesional.

Lo que sucede es que en los códigos de conducta profesional los colectivos profesionales proyectan lo que, desde sus conocimientos y desde la experiencia de la práctica de la profesión, significa ser un buen profesional en sus relaciones con los clientes o usuarios de su servicio, con los colegas y compañeros en general, con la organización en que trabaja, con su propia profesión y con la sociedad, y esto implica proceder con responsabilidad profesional.

Así, el modelo de buen profesional que presentan los códigos supone un profesional que conserva, mejora y actualiza su competencia profesional mediante la formación continua. Que cuida la calidad técnica y bumana del servicio. Que actúa con autonomia, porque tiene competencia, toma las decisiones que le corresponde y asume sus responsabilidades. Que autoevalúa las actuaciones y comportamientos profesionales para aprender de la experiencia. Y que, en su caso, responde a las expectativas de la ética cívica sobre su profesión, como el médico que atiende a un accidentado o en los ejemplos propuestos más arriba de compromiso con las exigencias de la justicia social.

\section{ENSEÑANZA-APRENDIZAJE DE LA ÉTICA PROFESIONAL EN LA UNIVERSIDAD}

\subsection{Planteamiento}

La información y reflexiones de los párrafos precedentes ofrecen fundamentación e ideas suficientes para el diseño de una propuesta sobre el planteamiento de la enseñanza-aprendizaje de la ética profesional en la universidad.

Un proceso que atañe al conjunto de los profesores por su importancia para la formación y en la vida de los futuros profesionales y porque, así como cada profesor contribuye a aportar desde su materia parte de la competencia que la universidad debe procurar a aquéllos, así también cada profesor debe contribuir aportando su grano de arena al aprendizaje de la ética profesional que ha de acompañar el ejercicio de esa competencia. Algo a lo que dan pie en algunos casos las propias materias que se explican (sobre todo las materias más directa o inmediatamente relacionadas con la praxis profesional); y con lo que, en cualquier caso, todos pueden colaborar dando ejemplo de valores y actitudes profesionales. 
Pero la información de los apartados anteriores ha puesto de relieve también que, por su conformación y contenidos, la éticas profesionales (que aplican la ética de las profesiones a cada profesión concreta) constituyen disciplinas filosófico-científicas aplicadas y, por lo mismo, merecen ocupar un lugar como materia o asignatura en los planes de estudios de todas las titulaciones.

Una asignatura que, completando lo expuesto con alguna perspectiva más, puede constar de cuatro bloques de contenidos, que pasamos a presentar.

\subsection{Bloques de contenidos y sugerencias metodológicas}

El primer bloque tendría como objetivos principales en el orden del conocimiento la comprensión de la importancia social y antropológica de la ética en la vida profesional:

- La importancia social de la ética profesional.

- El enraizamiento de esta ética en la realidad más profunda y esencial de la profesión, ya que la ética dirige la conducta humana a la búsqueda del bien y la profesión tiene su origen, justificación y claves últimas de comprensión en la aportación de algún bien a los demás y la sociedad.

- Y el hecho subsiguiente a lo anterior de que ejercitar la profesión con ética conlleva vivir con sentido en este orden de la existencia humana, sentirse realizado profesionalmente y pasar por las demás experiencias positivas recordadas más arriba.

Y tendría como objetivo principal en el orden de los valores y actitudes profesionales el deseo y la decisión de proceder éticamente en la vida profesional para alcanzar esa realización y felicidad profesionales.

Un segundo bloque - que no tiene que subseguir al anterior, ya que pueden coincidir o alternarse para motivar a los alumnos- lo constituyen temas que pueden ayudar al estudiante a una personalización universitaria de la ética.

Esta personalización de la ética a nivel universitario es conveniente para los alumnos que han tenido alguna asignatura de "ética" (o de "moral católica", en su caso) durante la educación secundaria, porque la dimensión ética de la vida humana es una realidad lo suficientemente importante como para repensarla en el inicio de la vida adulta con planteamientos y desde premisas de adulto. Y con mayor razón aún parece necesario este acercamiento personal a la ética para los estudiantes universitarios que no han tenido contacto con esta materia durante la educación secundaria (más de la mitad en mi experiencia de los últimos años).

Cuando hablo de personalización universitaria de la ética pienso, en primer lugar, en el conocimiento de la persona como sujeto moral; es decir, en el conocimiento y comprensión de los elementos que entran en juego en los fenómenos morales de las personas, de la relación entre ellos y de su importancia en la vida de la persona. Piénsese en los principios y valores morales que todas las personas 
tienen como norte del obrar bien y del obrar mal; en los condicionantes socioculturales y personales de ese sistema de principios/valores; en las actitudes (inclinaciones o predisposiciones) a actuar; en la problemática de la libertad en las decisiones; en los fenómenos de conciencia moral (de autodictamen sobre la decisión a tomar, de autoimpulso para hacer lo que se ve como bueno y evitar lo que se ve como malo, y de autosanción afectiva) que preceden, acompañan y subsiguen a las decisiones; en la responsabilización de la persona por las decisiones tomadas y acciones realizadas... (Cobo, 1993, 29-77).

Un conjunto de elementos que hacen de la vida moral una realidad extremadamente compleja, quizá la más compleja de la existencia humana, y cuya toma de conciencia suele ir acompañada de cuestiones tan propias del debate universitario como son:

- La importancia del seguimiento de la conciencia moral y del respeto a la misma.

- La problematicidad de la libertad (ibíd., pp. 235-262).

- O la necesidad de la ética como disciplina filosófica ${ }^{12}$ y, más en concreto, de una ética civil compartida por todos en las sociedades multiculturales ${ }^{13}$ y de una ética global en la sociedad mundial ${ }^{14}$.

El tercer bloque de contenidos de la asignatura lo constituyen los principios/valores de la ética de las profesiones. Un conjunto de principios para cuya mejor comprensión y valoración es conveniente explicar las dos fuentes de las que provienen y que los estudiantes suelen aceptar y asumir con facilidad, sobre todo cuando se aclaran con ejemplos.

Finalmente, el cuarto bloque corresponde a la ética profesional concreta que da nombre a la asignatura (ética profesional de...). Un bloque que puede abordarse por los siguientes caminos didácticos:

12. En todas las culturas ha habido y hay hombres que son considerados "modelos" de comportamiento ético; ahora bien, esos modelos no lo son para personas de otros tiempos o culturas, por lo que se hace necesaria la reflexión filosófica sobre el proceder más acorde con el ser humano en los distintos órdenes de su existencia en sus decisiones y actos presuntamente libres.

13. La necesidad y posibles componentes de una ética civil (conjunto de mínimos éticos consensuables y, por lo mismo, exigibles para regular la convivencia) son temas muy estudiados (un clásico en estos temas es Adela Cortina).

14. En cuanto a la ética global, es objeto de atención de la Unesco, que lo plantea buscando coincidencias transculturales (Informe mundial sobre la cultura 2000-2001. Diversidad cultural, conflicto y pluralismo. Madrid, Unesco/Mundi Prensa, 2001). Y también de la Conferencia Mundial de las Religiones (Ciudad del Cabo, 1998, Québec, 2001, Barcelona, junio de 2004). Otro camino para elucidarla lo ofrece el estudio de los objetivos de la educación que proponen los organismos internacionales más autorizados, entre los que se encuentran los más importantes y necesarios objetivos de la educación ética (cf. COBo [2001]: Educación ética y nueva sociedad mundial, Revista de Educación, número extraordinario 2001 dedicado a Educación y Globalización, 289-315). 
- Apoyando la presentación de todos los temas anteriores con ejemplos de esta ética profesional.

- Utilizando los métodos de solución de problemas y las técnicas de estudio de casos profesionales éticamente dilemáticos, unos y otros tomados del ejercicio real de la profesión cuya ética profesional se estudia.

- Leyendo los artículos del código ético o deontológico correspondiente, ponderando el principio o principios de la ética de las profesiones que se actualiza en cada uno de ellos.

Es importante subrayar - y con ello termino este apartado- que el hecho de que lo hayamos presentado como un cuarto bloque de contenidos no quiere decir que deba remitirse cronológicamente al final de la asignatura.

Ya hemos indicado que uno de los métodos de tratamiento didáctico de este bloque es la utilización desde el comienzo del curso de ejemplos de la ética profesional objeto de estudio. Así, aunque puede ser muy clarificador en algunos temas recurrir a ejemplos tomados de otras profesiones, es lógico que se concrete y aplique con ejemplos, datos y situaciones de la profesión y de la ética profesional objeto de estudio cuando se habla de la importancia social de la ética profesional, o de cómo toda profesión es necesaria socialmente y tiene como razón de ser procurar algún bien, o de cómo actuando correctamente el profesional vive con sentido y se siente realizado en su trabajo, o del sentido de los distintos principios éticos.

Asimismo, es importante dedicar ratos de clase desde el principio al estudio de casos (aunque no se haya estudiado todavía la teoría para resolverlos) y recordar artículos del código ético o deontológico en la explicación de los temas o el estudio de casos, porque todo ello contribuye a incrementar el interés por la asignatura y ayuda a tomar conciencia de la presencia de la ética a lo largo y ancho de la vida profesional.

\section{LA ENSEÑANZA-APRENDIZAJE DE LA ÉTICA PROFESIONAL EN LA UNIVERSIDAD ESPAÑOLA}

Parece lógico que en una revista española este artículo no termine sin alguna referencia a la situación de la enseñanza-aprendizaje de la ética profesional en la universidad española.

Una referencia que no es fácil concretar y que haremos glosando tres ideas principales: a) hay una sensibilidad creciente sobre la necesidad de incluir la ética profesional en el currículum de la educación universitaria; b) hay ya experiencias importantes de esta inclusión de la ética profesional en el currículum en algunas titulaciones y universidades; c) y proliferan otras muchas experiencias que hacen presente la ética profesional en la educación superior.

Comenzando por lo primero, la sensibilidad creciente sobre la necesidad de incluir la ética profesional en el currículo de la educación universitaria, recordemos como muestras de la misma las "Reflexiones de la Comunidad Universitaria en 
torno a la Ética Profesional en la Universidad" (Universidad de Salamanca, 1998) ${ }^{15}$. El ciclo de conferencias organizado por el Consejo Social de la Universidad de Alicante (febrero del 2002) con el objeto de relanzar el proyecto de incluir la ética profesional en las carreras ${ }^{16}$. Y también el III Symposium Iberoamericano de Docencia Universitaria. Pedagogía Universitaria: Hacia un Espacio de Aprendizaje Compartido (Universidad de Deusto, Bilbao, 21 a 24 de enero de 2004). En la presentación del Grupo de Discusión 2 que tiene como título "El desarrollo de valores en la Universidad" y que coordinan Itziar Eléxpuru y Antonio Bolívar se concede una atención preferente a la ética profesional, que se debe incluir en el currículum de la educación universitaria" y para la que se proponen líneas metodológicas, intercambios de experiencias y buenas prácticas, etc.

Son igualmente muestras de esta sensibilidad y atención creciente a la ética profesional en la universidad las numerosas publicaciones que aparecen (estudios, manuales, artículos) y la gran cantidad de actividades (seminarios, cursos...) que se organizan en los centros de educación superior ${ }^{17}$.

Pasando ahora a la presentación de experiencias importantes de inclusión de la ética profesional en el curriculum en algunas titulaciones y universidades, hay que destacar, en primer lugar, que desde 1990 existe una titulación, la de Enfermeria, que tiene la materia de "Legislación y ética profesional. como asignatura troncal en el plan de estudios ${ }^{18}$, ejemplo seguido más recientemente por la titulación en Fisioterapia. Asimismo, es de notar que en España hay universidades que integran ya oficialmente la ética profesional en sus titulaciones, como la Universidad Politécnica de Valencia ${ }^{19}$ y el grupo de Universidades y Centros Superiores de inspiración católica (Navarra, Deusto, Comillas (Icai-Icade), Pontificia de Salamanca...).

15. 15 escritos publicados en http:/www3.usal.es/-adux/artic/artic.htm.

16. "Pretendemos entregar unas conclusiones de este ciclo al Ministerio de Educación para invitar a la Administración a que implante la ética profesional como asignatura en todas las titulaciones universitarias, porque lo cierto es que los campus están huérfanos de ética* (R. Pérez Herranz, coordinador del ciclo. Información publicada en el periódico Las Provincias el 12/02/2002.)

17. Entre las publicaciones, estudios como el de DE VICENTE; Bolívar y otros (2001), y los estudios-manuales de la colección "Ética de las Profesiones" (Desclée), proyecto que llevan a cabo profesores de los Centros Universitarios de la Compañía de Jesús en España.

En cuanto a las actividades mencionadas, el buscador Google responde a la "búsqueda en España" de los términos relacionados "Ética Profesional Universidad" con 12.600 entradas (para "Ética Profesional. las entradas "en español" son 151.000 y "en España" 28.800).

18. Real Decreto 1466/1990, de 26 de octubre, por el que se establece el título universitario oficial de diplomado en enfermería y las directrices generales propias de los planes de estudios conducentes a la obtención de aquél. En el Anexo, directriz tercera (relación de materias troncales, contenidos, créditos y vinculación a áreas de conocimiento) se dice: Legislación y Ética profesional. Normas legales de ámbito profesional. Códigos deontológicos y otras recomendaciones éticas. Créditos: 2. Enfermería, Toxicología y Legislación sanitaria, Filosofía del Derecho, moral y política y Derecho administrativo.

19. La LPV tiene una Unidad docente de Cooperación para el Desarrollo y Ética que imparte en las diversas titulaciones las asignaturas de Introducción a la Cooperación al Desarrollo, Proyectos de Cooperación para el Desarrollo, Voluntariado de Organizaciones no Gubernamentales, Ética Aplicada, Engineering Ethics, Ética de la Empresa y Filosofía para Ingenieros. 
Finalmente, en lo que se refiere a la tercera idea apuntada de otras experiencias que bacen presente la ética profesional en la educación superior, concretando algo más lo indicado más arriba sobre las numerosas actividades que se organizan (cursos, seminarios, jornadas...), parece que los ámbitos que más se prestan a ello son los de la salud (en medicina interesan particularmente los problemas de bioética y los temas legales), los de ciencias bumanas y sociales (educación, trabajo social, psicología...) y los de ciencias económicas y empresariales.

A propósito de este último campo, en algunas Facultades de CC.EE. y EE se tienen seminarios sobre ética empresarial; en otras hay alguna asignatura de libre elección sobre esta materia; alguna universidad ha ofertado plazas de profesores en el tema: caso de la Universidad de Extremadura recientemente ${ }^{20}$. Ahora bien, el balance no es muy positivo en cuanto a la institucionalización de este tipo de estudios, aun cuando el tema de la ética empresarial va siendo cada vez más contemplado como algo importante. Es curioso, por lo demás, constatar que en ciertas Facultades de Filosofía o Humanidades de universidades "nuevas" y con sesgo moderno - caso de la Jaume I de Castellón - se explique ética empresarial.

En lo que se refiere a las "Bussines Schools" (escuelas de negocios) el asunto está mucho más generalizado, si bien parece notarse un cierto pudor a la hora de hablar de "Ética". Se tiende a hablar más bien de "Responsabilidad Social de la Empresa", "Ciudadanía Empresarial", "Buenas Prácticas”..., temas profundamente emparentados con la ética empresarial, pero no tan global y fundamentalmente comprometedores como ella.

\section{BiBliogRAFÍA}

Altarejos, F.; Ibáñez Martín, J. A.; Jordán J. A. y Jover, G. (1998) Ética docente. Elementos para una deontologia profesional. Barcelona, Ariel.

Bárcena, F.; GiL, F. y Jover, G. (1991) La dimensión ética de la actividad educativa, Bordón, vol. $43, \mathrm{n}^{\circ} 3$.

Bermejo, F. J. (2002) Ética del Trabajo Social. Colección "Ética de las Profesiones". Bilbao, Desclée.

CAMACHO, I.; FernándeZ, J. L. y Miralles, J. (2002) Ética de la Empresa. Colección "Ética de las Profesiones". Bilbao, Desclée.

CAMPS, V. y Giner, S. (1998) Manual de civismo. Barcelona, Ariel.

Cátedra de BioÉtica de la Universidad Pontificia de Comillas. Publicaciones sobre ética médica y bioética (ver Catálogo de la UPCO).

Сово, J. M. (1993) Educación ética para un mundo en cambio y una sociedad plural. Madrid, Endimión.

- (1995) Educación moral para todos en secundaria. Madrid, Narcea.

20. Resumo aquí algunas opiniones suscitadas en una conversación sostenida en noviembre del 2003 con José Luis Fernández Fernández, director de la Cátedra "Javier Benjumea de Ética Económica y Empresarial de la Universidad Pontificia de Comillas de Madrid. 
- (2000) Ética Profesional en Ciencias Humanas y Sociales. Madrid, Huerga y Fierro. Aporta en Apéndice los textos completos de los Códigos de Conducta Profesional de los Educadores (Pedagogos, Docentes...) (159-166), Psicólogos (166-180), Orientadores (Psicopedagogos) (181-188), Trabajadores Sociales (188-204) y Logopedas (204-209).

- (2001) Educación ética y nueva sociedad mundial, Revista de Educación, número extraordinario dedicado a Educación y Globalización, 289-315.

- (2003) Ética y utopía, Letra Internacional, 78, Primavera 2003, 36-38.

- (2003) Formación universitaria y educación para la ciudadanía, Revista de Educación, número extraordinario dedicado a Ciudadanía y Educación, 359-375.

Comisión Olivencia (1997) Código del buen gobierno de las sociedades. Madrid (protocolo ético revisado en 1999).

Cortina, A. (1994) La ética de la sociedad civil. Madrid, Anaya/Alauda.

- (ed.) (1994) Ética de la Empresa. Claves para una nueva cultura empresarial. Madrid, Trotta.

Cortins, A. y Conill, J. (dirs.) (2000) 10 palabras clave en ética de las profesiones. Estella (Navarra), Ed. Verbo Divino.

Cortina, A. y GarCía-MARZÁ, D. (eds.) (2003) Razón pública y éticas aplicadas. Los caminos de la razón práctica en una sociedad pluralista. Madrid, Tecnos.

DE VICENTE BOLÍVAR, A. y otros (2001) La formación práctica del estudiante universitario y los códigos deontológicos del ejercicio profesional. Madrid, MECD, Dirección General de Universidades. Informe final de investigación.

Díez ANDINo P.; MARINAS, J. M. y WITT, N. (2002) Ética de la comunicación: problemas y recursos. Madrid, Edipo.

Domingo Moratalla, A. (1997) Ética y voluntariado. Una solidaridad sin fronteras. Madrid, PPC.

ETXeberRía, X. (2002) Temas básicos. Colección "Ética de las Profesiones". Bilbao, Desclée.

França, O. y TaRRagó, O. (1996) Ética para Psicólogos. Bilbao, Desclée.

GÓmez PÉRez, R. Deontología jurídica. Ediciones de la Universidad de Navarra, S.A. (EUNSA).

HoRTAL, A. (1994) La ética profesional en el contexto universitario (Lección inaugural). Madrid, Public. de la upco.

- (2002) Ética general de las Profesiones. Colección "Ética de las Profesiones". Bilbao, Desclée.

IZQUERDO, M. (1989) La responsabilidad del profesional liberal. Madrid, Reus.

LÓPEZ DE LA VIEJA, M. a Teresa (2000) Principios morales y casos prácticos. Madrid, Tecnos.

Martínez, M.; BuXarrais, M. R. y Esteban, F. (2002) La universidad como espacio de aprendizaje ético, Revista Iberoamericana de Educación, $\mathrm{n}^{\circ} 29,17-43$.

MelÉ CARNÉ, D. (coord.) (2a ed.) (1999) Ética de la actividad financiera. Pamplona, EUNSA.

Pontificio Consejo para las Comunicaciones Sociales (4 de junio de 2000) Ética de las Comunicaciones Sociales. HYPERLINK http://zenit.org/spanish/archivo, 30 de marzo de 2000.

REviSTA ICADE (1994) 33. Deontología de los profesionales del derecho. Madrid, Public. UPCO.

WADWLieY, A. y BlaSCO, T. (1995) La ética en la investigación y la práctica pedagógicas. Barcelona, Ariel.

Vielva, J. (2002) Ética de la enfermería. Colección "Ética de las Profesiones". Bilbao, Desclée. 